\title{
USDA to Require Research Facilities, Dealers, and Exhibitors to Keep Veterinary Medical Records
}

On 11 April, the US Department of Agriculture, Animal and Plant Health Inspection Service (USDA, APHIS) proposed the amendment of the Animal Welfare Act regulations "to require that research facilities, dealers, and exhibitors maintain medical records as part of their program of adequate veterinary care ... as a means of communication concerning the care being provided to animals and to ensure that the animals receive adequate veterinary care ${ }^{1}$."

Subparts C and D of 9 CFR part 2 of the animal welfare regulations require each research facility, dealer, and exhibitor to have an Attending Veterinarian and maintain a program of adequate veterinary care. Although the regulations do specify several elements constituting a program of adequate veterinary care that imply the use of medical records, they do not currently require the keeping of medical records.

In justifying the need to maintain veterinary medical records, the USDA stated that adequate veterinary care to animals depends on accurate medical records; in addition, such records provide a means of communication between caregivers and provide a tool for USDA inspectors to verify the adequacy of animal care.

The USDA's proposed amendments to 9 CFR part 2 would add a new section requiring the maintenance of legible medical records as an additional element of the program of adequate veterinary care. Each medical record would have to include "(1) The identity of the animal (with the exception that routine husbandry, such as vaccinations, preventive medical procedures, or treatments, per-

\begin{abstract}
Regulation Updates
FDA Issues Final Rule for Records and Reports on Experiences with Animal Drugs

On 31 March, the Food and Drug Administration issued a final rule that reduces the agency's requirements for records and reports on experiences with approved new drugs for animals ${ }^{2}$. The rule, which goes into effect on 30 June, significantly reduces the previous requirements of both reporting and record keeping on experiences with New Animal Drug Applications (NADA) and Abbreviated NADAs (ANADA), as compared with current regulations, and incorporates many of the industry comments on earlier drafts. This final rule redefines the kinds of information that must be maintained and submitted by new animal drug applicants for an NADA or ANADA. It revises the timing and content of certain reports to enhance their usefulness, provides for the protection of public and animal health, and reduces the record-keeping and reporting requirements.
\end{abstract}

\section{Sweden Bans Experiments Using Great Apes, Gibbons}

Effective in June, great apes and nine species of gibbons will be exempt from use as research subjects in Sweden ${ }^{3}$. Although none of these species is currently being used in research in that country, the new legislation marks an ideological victory for animal rights organizations that have been campaigning. Sweden joins Great Britain, Japan, New Zealand, and the Netherlands on a list of countries that have outlawed research on these animals. Swedish researchers will still be permitted to use great apes and gibbons in noninvasive behavioral studies.

formed on all animals in a group (or herd) may be kept on a single record); (2) the date, description of the problem, pertinent history, observations, examination findings, test results, and plan for treatment and care with a tentative diagnosis and a prognosis, when appropriate; (3) the type and chronology of treatment procedures performed, the context of the problem to which the treatment procedures pertain, and the identification of the medication used, the date given, dosage, route of administration, frequency, and duration of treatment; (4) the names of all vaccines administered and the dates of vaccination; and (5) the dates and results of all screening, routine, or other required or recommended tests ${ }^{1}$."

The USDA proposed further to amend the record-keeping standards for research facilities to "require that medical records be kept for 1 year after the disposition of the animals and that one copy of those records be provided to subsequent own- ers of the animals or to any person to whom the animals will be consigned ${ }^{1}$."

APHIS does not anticipate that these changes will result in a great increase in burden to regulated facilities, because most facilities already comply with these proposed minimum standards for medical records. However, some costs may result from the need to record and maintain medical records under this proposed rule, although the USDA considers them to be minimal.

\section{References}

1. USDA, APHIS. Proposed rule. Animal welfare; medical records. Federal Register 68 , 17752-17755 (11 April 2003).

2. FDA. Withdrawal of interim final rule and issuance of final rule. Records and reports concerning experience with approved new animal drugs. Federal Register 68 15355-15369 (31 March 2003).

3. Animal Rights Sweden. Sweden bans experiments on great apes (9 April 2003). http://www.djurensratt.org/articles/article. asp?id=615 